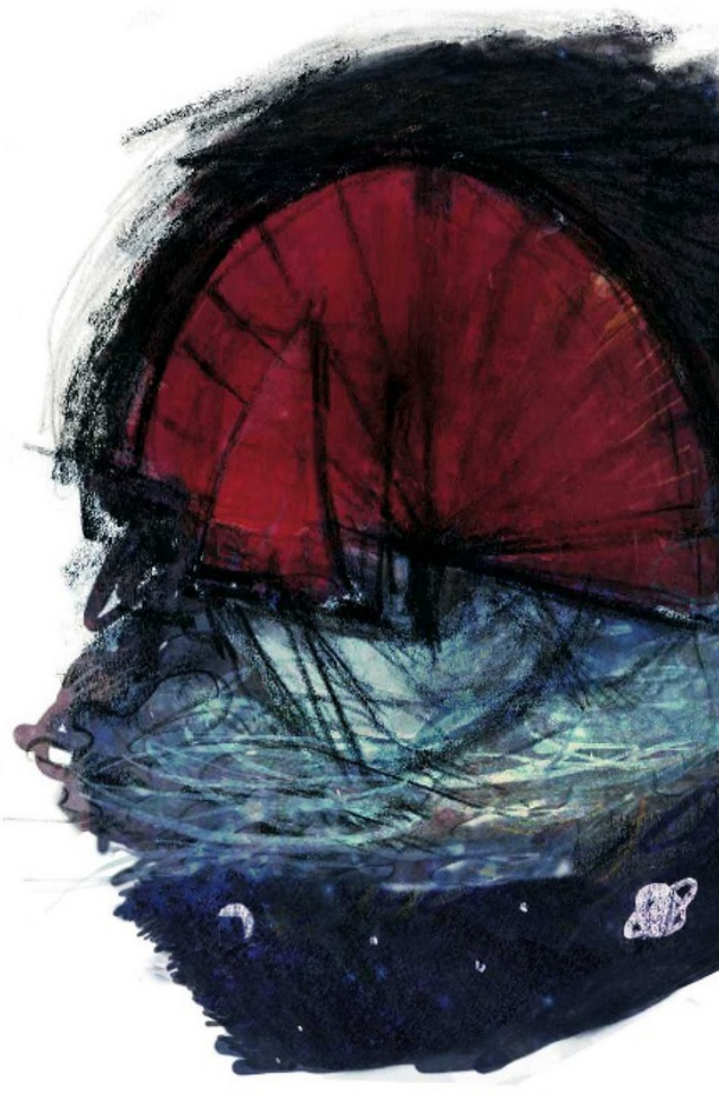

dooming the mission to failure before the sail mechanism could even be tested. Although the test was inconclusive, the perceived lack of success reflected badly on the solar-sail initiative itself.

Now the tide is beginning to turn. Groundbased tests in Europe and the United States have successfully deployed sails of about 20 square metres thanks to improvements in sail-opening mechanisms. The German Aerospace Centre has used plastic booms reinforced with carbon fibre, and NASA has used inflatable booms that harden when exposed to the coldness of space. Even more impressively, the Japanese space agency JAXA has carried out two successful sub-orbital deployment tests. Made of reflective films 7.5 micrometres thick and some 10 metres in diameter, the sails were flown to an altitude of 122 kilometres, where one opened up like a clover-leaf, the other like a fan. JAXA followed this up two years later in 2006, with a successful 20-metre-wide sail deployment from a balloon at an altitude of 35 kilometres.

Some space missions can be performed
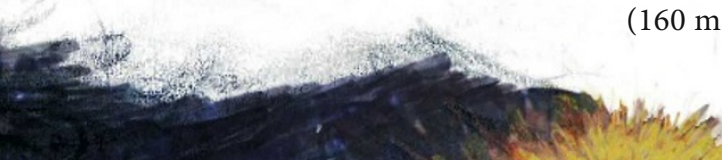

A
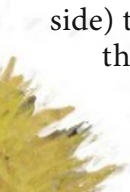

holds the sail in space, it can be angled so it hovers like a kite over the poles of a planet, making solar-sail craft ideal anchors for communications and remote-sensing satellites.

Of course, there are limitations. Solar sails lose their power and manoeuvrability when they are far from the Sun, out beyond Jupiter. They are also unable to assume low orbits around planets with atmospheres because the sails are susceptible to drag.

Suitable for aerospace students and keen enthusiasts alike, this book may one day inspire some of them to build a solar-sailpowered vessel. Although there is still a long way to go, this useful volume will help speed up that day. with solar sails Placing a satellite in a polar orbit around the Sun using a rocket requires a large expenditure of energy, and hence fuel. A craft propelled by a solar sail would take only five years to fly there from Earth but would require a huge sail area of 25,600 square metres

Stuart Clark is a visiting fellow at the Centre for Astrophysics Research, University of Hertfordshire, Hatfield, AL10 9AB, UK. He is author of The Sun Kings.

\title{
Imaging the unseen
}

\section{Six Stories from the End of \\ Representation: Images in Painting, \\ Photography, Astronomy, Microscopy, \\ Particle Physics, and Quantum \\ Mechanics, 1980-2000 \\ by James Elkins \\ Stanford University Press: 2008. \\ 320 pp. $\$ 65$}

\section{Felice Frankel}

In Six Stories from the End of Representation, James Elkins makes a brave and laudable attempt to address in parallel the communication of ideas in both the sciences and the humanities.

"I believe that the clearest, most fruitful response to the abyss between the humanities and the sciences is to set out the disciplines, in detail, side by side, and let them tell their stories in their own languages. As far as I can see, that is the only way to produce a book that can be read by scientists and humanists without the creeping feeling that their disciplines are better explained - or explained away - by someone who does not really understand them," he writes.

Elkins' approach struck me as exciting. A respected and prolific scholar, he promised a view of scientific images distinct from that taken by other art historians. I was eager to see the images to which he was going to introduce us, and how they were to "tell their own stories". After all, Elkins declared that "the images came first" in preparing the book, and that the images "are among the best that have been made in the last several decades".

\section{Science of Describing: Natural History in Renaissance Europe}

by Brian W. Ogilvie (Univ. Chicago Press, $\$ 27, £ 14$ ) In the mid-sixteenth century, naturalists developed tools for observing and describing nature, enabling them to assess and share their findings with others. Interpreting this change over four generations, Brian Ogilvie "has written the story of how science constantly reinvents itself, seen through the lens of the pre-linnaeans", wrote Sandra Knapp (Nature 442, 871; 2006).

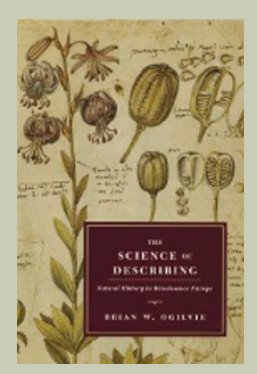

\section{Digital Art (Revised Edition)}

by Christiane Paul (Thames \& Hudson, E8.95)

The digital format offers new possibilities for artistic expression. In an updated volume, Christiane Paul addresses how viewers interact with such works, and explores links with artificial life and intelligence, activism and networks, as well as the collection, presentation and preservation of digital art.

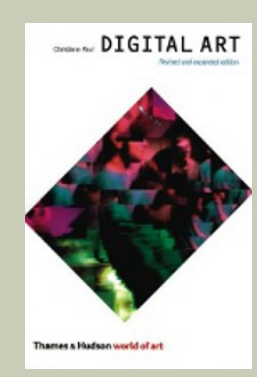


So I can imagine Elkins's horror (my response, were I in his shoes) to discover the publisher's plan to illustrate this book of images by means of the insertion of a small collection of colour plates smack in the middle of the edition, forcing the reader to hunt through the text for reference to them, with the remaining majority of the images placed within the narrative but reproduced in grainy black and white on cheap paper. Surely publishing a book about seeing images warrants allowing the reader to see the images?

Beyond the layout, Elkins's approach offers a new way of making us look more closely at how we depict objects. The book is spread across six chapters, and includes more than 100 visual representations drawn from art and science created between 1980 and 2000. The art collection includes photography, sculpture and painting: works by Agnes Martin, Gerhard Richter, Sol LeWit and Jasper Johns, among others. The science collection is also broad, ranging from representations of the very small (particle physics) to the very large (astronomy), and including TEMs (transmission electron micrographs) of influenza virus, STMs (images from scanning tunnelling microscopes) of gold surfaces, Feynman diagrams of particle interactions and Hubble Space Telescope images of the galaxies.

Elkins informs us that these images are "objects that literally don't exist ... abstractions of abstractions, feeble symbols of objects that have no reality of their own". Leaving the philosophy of existence to other experts, I will not delve here into an argument of how many of the book's science images are representations of objects that do have a reality of their own. It is true that all images in science are representations of data of some sort, but I'd like to think those data derive from evidence of existence, even if transitory.

In telling his Six Stories from the End of Representation, Elkins stops short of making explicit links between images. He uses what he calls a "non-causal narrative", where "it is the reader's task to decide what threads might tie the images together and just how tightly they should be pulled". His juxtaposition of the

\section{Walter Rothschild: The Man, the Museum and the Menagerie}

by Miriam Rothschild (Natural History Museum, E9.99)

Walter Rothschild, one of Britain's most famous zoologists and eccentrics, amassed a huge collection of animals. His life, work and family are honestly and affectionately documented by his niece, the late Miriam Rothschild.

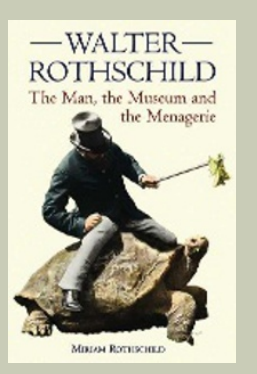

Evolution for Everyone: How Darwin's Theory Can Change the Way We Think About Our Lives by David Sloan Wilson (Delta, \$15)

Covering subjects from dung-beetle infanticide to human religion, this book emphasizes the role of group selection in evolution in modern human life. "It is a delicate and subtle debate and Sloan Wilson's popular accounts ... make for enjoyable and thoughtful reading," wrote Mark Pagel (Nature 447, 533; 2007). simply depict objects, but demonstrated how some objects resist depiction."

There is much I might challenge in Elkins's attempt to get the two cultures to talk to each other - first and foremost is his selection of "the most important" images. His choices are, after all, personal, and the book seems to be more a journal collection of his favourite things rather than a thesis. To my mind they are a haphazard collection. Perhaps this reviewer has seen too many cloudchamber images of sub-atomic particle traces; although we must always remember that those stunningly intriguing

patterns - chosen for the cover of the book - are not the particle itself.

The title's suggestion that this period is the end of representation cannot be further from the truth. At least in science, the end of the twentieth century was the beginning of representation. $\mathrm{He}$ is correct in saying: "It strikes me that those makers are most fully preoccupied by whatever cannot be put in a picture," suggesting the representations they are creating are so inadequate that they lead to further quesphotograph of the star WolfRayet 104 and Edward Ruscha's intentionally blurred acrylic, F House, is used as an example of an "illusory coherence brought on by certain habits of seeing" - blurring, I uppose in this case.

For Elkins, "it became clear that the images were the results of investigation into the limits of representation. Few of them contained sharp ficult to unded objects, and in most it was difadequate representation. They seemed to have a common theme: they were images that did not tions. Indeed, that is precisely the frustration that has so profoundly informed our present obsession in the laboratory with new and extraordinary visual expressions of science. We are living in an exciting time, in which we continue to ask how we might represent the unrepresentable.

Felice Frankel is a senior research fellow in the Faculty of Arts and Sciences at Harvard University's Initiative in Innovative Computing, 60 Oxford Street, Cambridge, Massachusetts 02138, USA. She is co-author of On the Surface of Things, Images of the Extraordinary in Science.

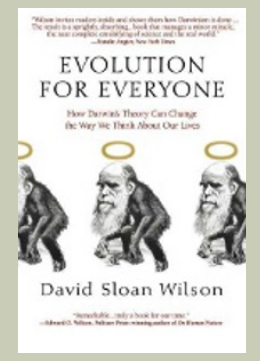

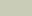

@2008 Nature Publishing Group 